\title{
PINTURAS Y ESCULTURAS COMO METÁFORAS ARGUMENTALES EN EL CINE DE PEDRO ALMODÓVAR
}

\author{
PAINTINGS AND SCULPTURES AS ARGUMENTAL \\ METAPHORS IN THE PEDRO ALMODÓVAR CINEMA
}

\author{
Gloria Camarero Gómez \\ Universidad Carlos III de Madrid. España \\ ORCID: 0000-0001-8126-6940 \\ gloria.camarero@uc3m.es
}

\begin{abstract}
El presente trabajo estudia la presencia de pinturas y esculturas en el cine de Pedro Almodóvar y constata como estas, muchas veces, no constituyen meros elementos de atrezo, sino que tienen un valor de significado. Son metáforas argumentales, "claves para descifrar". Definen los espacios de representación, caracterizan el comportamiento y los sentimientos de los protagonistas, aportan las claves temáticas, ilustran la acción y referencian tiempos y lugares. Incluso, diferencian las clases sociales. Se analiza así, el sentido que alcanzan obras de Tiziano, Warhol, Tàpies, Úrculo, Barceló, Bourgeois o Navarro en la filmografía almodovariana en general y en los ejemplos concretos de La piel que habito (2011), Julieta (2016) y Dolor y gloria (2019).
\end{abstract}

Palabras clave: cine y pintura; cine y escultura; Pedro Almodóvar; escenografía; Dolor y gloria.

This paper studies the presence of paintings and sculptures in the Pedro Almodóvar's cinema and exposes how, many times, they are not mere elements of props but have a meaning value. They are plot metaphors, "keys to deciphering". They define the spaces of representation, characterize the behavior and feelings of the protagonists, provide the thematic keys, illustrate the action and reference times and places. They even differentiate social classes. Thus, the paper analyzes the meaning that works by Tiziano, Warhol, Tàpies, Úrculo, Barceló, Bourgeois or Navarro reach in Almodovarian filmography in general and in the concrete examples of La piel que habito (2011), Julieta (2016) and Dolor y gloria (2019). y gloria

Keywords: cinema and painting; cinema and sculpture; Pedro Almodóvar; scenography; Dolor 


\section{INTRODUCCIÓN}

La presencia de pintura, escultura y objetos de diseño en el cine de Pedro Almodóvar es una constante. En algunos casos se integran en los decorados sin otra finalidad que la meramente decorativa. Ha sido lo habitual cuando las casas de sus amigos se han convertido en escenario fílmico. La de Bom (Alaska) en Pepi, Luci, Bom y otras chicas del montón estaba en pleno barrio de Malasaña en Madrid, en la calle de la Palma número 14, y era la vivienda-estudio real de la pareja de pintores Costus (Juan Carrero y Enrique Naya), los cuales alcanzaron mucho reconocimiento durante los años de la Movida con su particular estilo reminiscente del Pop Art, de tono crítico y sarcástico ${ }^{1}$. Ese piso se convirtió en uno de los centros neurálgicos del movimiento y Francisco Umbral lo llamó "la casa-convento de las estrellas descarriadas"2. Los cuadros en acrílico más famosos de los propietarios, del tipo de Marina o los retratos de personajes del papel cuché, inspirados en las fotografías publicadas por las revistas del corazón, como los de Carmen Polo de Franco, Lola Flores, la reina Fabiola de Bélgica o el sha de Persia y Farah Diba, actualmente propiedad de Alaska, colgaban en las paredes de la residencia y los vemos en la película, según estaban in situ. Por su parte, la casa de Elena Benarroch, en la madrileña calle Zurbarán, simula ser, en Julieta, la de Claudia (Pilar Castro) y su hija Beatriz adolescente (Sara Jiménez). Contiene numerosas obras de arte contemporáneo, que nutren una consolidada colección personal de la propietaria, muchas de las cuales son esculturas circulares en hierro, piedra y bronce, realizadas por Adolfo Barnatán, hoy ex marido de la peletera-diseñadora. La cámara se detiene en mostrar unas y otras. No pasan desapercibidas. A su través se define un gusto, un estilo y un estatus, que es el de la moradora en la realidad y en la ficción. Reykjavík de Richard Serra constituye el fondo ante el que Julieta joven (Adriana Ugarte) comunica a Antía adolescente (Priscila Delgado) que su padre ha fallecido (Figura 1). No tiene valor de significado. Forma parte del escenario natural del filme.

Pero, con frecuencia, estas obras son metáforas argumentales, significantes muy vinculados a la vida de los protagonistas y exceden la función del atrezo. Áurea Ortiz y María Jesús Piqueras, en su ya clásico libro La pintura en el cine. Cuestiones de representación visua ${ }^{3}$, hablaban de la posibilidad de que los cuadros en el cine sean "claves para descifrar". La filmografía almodovariana encaja en esa categoría y no constituye una excepción. Baste recordar La edad de la inocencia (Martin Scorsese, 1993), en la que había abundancia de pinturas. No solo estaban ahí para testimoniar la opulencia de la burguesía neoyorquina del siglo XIX que relata, sino que expresan la forma de ser de los protagonistas. El retorno de la

\footnotetext{
1 Arroyo Fernández, 2011: 256-274.

${ }^{2}$ Umbral, 1981.

${ }^{3}$ Ortiz/Piqueras, 1995: 167.
} 
primavera de Bougereau, con su destacado desnudo femenino, aparece en el salón de la casa de los Beaufort, lo que constata el carácter transgresor y tendente a la provocación de estos. Los Van der Luyden son mucho más conservadores y ello se expresa por los lienzos que decoran su comedor: retratos ingleses, perfectamente ordenados. La condesa Olenska es distinta y en su residencia tiene pinturas distintas: Las caricias de Fernand Khnopff y cuadros de los macchiaioli italianos de pincelada suelta, interpretaciones y formatos nada habituales y, menos aún, en comparación con las pinturas que adornan las viviendas de los otros protagonistas de su misma clase social en la película ${ }^{4}$.

La selección de todas y cada una de las pinturas y esculturas que se integran en los filmes del director manchego hablan de su propia biografía y responde a criterios autobiográficos. Algunas le pertenecen y en todos los casos son, según ha dicho él mismo, "un verdadero álbum de recuerdos de mi vida privada"

Almodóvar da a estas obras un significado nuevo, que no tienen cuando están expuestas en otros contextos, fuera del plató de rodaje. Definen los espacios de representación, caracterizan el comportamiento y los sentimientos de los protagonistas. A veces, son el espejo en el que se reflejan estos. Aportan las claves temáticas, ilustran la acción y referencian tiempos y lugares. Incluso, diferencian las clases sociales. Uno de los muchos ejemplos de esto último, lo podemos ver en ¿Qué he hecho yo para merecer esto? y comprobar cómo mientras en el minúsculo piso de Gloria (Carmen Maura), en el madrileño barrio de la Concepción, abundan los papeles pintados, los tapetes de ganchillo y alguna lámina de paisaje low cost, en las viviendas de sus "jefes" dominan los trabajos de Úrculo, Tàpies o Barceló. A cada grupo social le corresponden unos gustos estéticos determinados que se manifiestan en las piezas que exhiben en sus residencias.

Con ese objetivo de ser metáfora argumental están Pistolas, Revólveres y Fusiles de Andy Warhol en Los abrazos rotos como clara alusión a la violencia desencadenada, la que ejemplifica también la presencia de La muerte de Viriato de José Madrazo, en la casa de Elena (Fancesca Neri), en Carne trémula. En el primer caso hay más pinturas, especialmente en el domicilio de Ernesto Martel (José Luis Gómez), que, según el guion, es consolidado coleccionista de arte. En su comedor destaca el bodegón Manzanas, del artista barroco español Juan Bautista de Espinosa, realizado en el siglo XVII y que se conserva en el Museo del Prado. Es este, en realidad, un cuadro de pequeño tamaño $(21$ x $36 \mathrm{cms})$ que se ha ampliado considerablemente en el decorado y que adoptó el uso de superficies pétreas como recurso para incrementar el realismo, lo que fue habitual en los bodegonistas madrileños del periodo. "Habla" de la tentación, la deslealtad, las pasiones contenidas y los deseos insatisfechos que rigen el relato. Son las actitudes de Martel y

\footnotetext{
${ }^{4}$ Huguet/Camarero, 2000: 139-158.
}

5 Almodóvar, 1993: 66. 
Lena (Penélope Cruz). Por ello, es fondo de los mismos y motivo de interrelación entre ellos (Figura 2).

La misma película incluye Chicas y maletas, homenaje argumental y escenográfico a Mujeres al borde de un ataque de nervios ${ }^{6}$. Las manzanas de Espinosa se han transformado en la Mela, diseñada por Enzo Mari, en 1963, dentro de la serie Della Natura, más acorde con la modernidad del decorado y desprovista del significado que tenían aquellas (Figura 3).

\section{LA TRANSLACIÓN DE PERSONALIDAD: DEL ARTISTA AL PERSONAJE FÍLMICO Y OTRAS CUESTIONES}

Un ejemplo representativo al respecto lo constituye La piel que habito, en la que las referencias escultóricas tienen una significación especial. Convierte la obra de Louise Bourgeois en referente incuestionable y en válvula de escape y garantía de salud mental para Vera (Elena Anaya) durante su encierro involuntario en casa del doctor Ledgard. La joven conoce a esta artista porque sus raptores le entregan un libro de aquella para que se entretenga mientras permanece recluida y es a la vista de los trabajos de la escultora cuando decide dedicarse a reproducirlos como terapia. Lo ha reconocido el propio Almodóvar en los títulos de créditos finales del filme: "Gracias a Louise Bourgeois, cuya obra no solo me ha emocionado, sino que sirve de salvación al personaje de Vera". Ya antes explicó que dichas referencias no fueron producto de la casualidad: "Vi una retrospectiva en la Tate Modern y detecté una conexión clarísima con lo que quería contar. Me fijé en la escultura de una cabeza, en la que había un perfil masculino y otro femenino, con un niño en el interior. Son imágenes en las que se combinan los géneros, las edades... El arte de Louise Bourgeois es lo que permite sobrevivir al personaje de Vera. Imitando su obra, ella consigue salir de su pozo. El arte tiene una función salvadora"?.

La protagonista hace suya la frase Art is a guaranty of sanity de esta creadora que incluyó de los textos que conforman la serie de nueve dípticos realizada en 1999, titulada ; What is the Shape of this Problem? y dibuja en la pared de su habitación las fechas de los días que pasan, palotes, frases y obras de Bourgeois ${ }^{8}$.

\footnotetext{
${ }^{6}$ Poyato, 2012: 7-23.

${ }^{7}$ http://todopedroalmodovar.blogspot.com/2016/02/el-arte-de-almodovar-louisebourgeois.html (19-7-2019).

${ }^{8}$ Thibaudeau entiende que estas realizaciones de Vera en la pared-pantalla de su habitáculo evocan también el ejemplo de Fernando Oreste Nannetti, quien "grabó durante nueve años, con la punta de la hebilla de su chaquetilla, las paredes del hospital psiquiátrico de Volterra (Toscana) donde estaba internado" y de "Jeannot, campesino de Béarn (Francia), quien grabó con un punzón en letras mayúsculas el suelo de madera de la habitación donde él mismo se había encerrado”. Thibaudeau, 2013: 199.
} 
Tiene mucho de diario. Es su manera de resistir. No es el único personaje almodovariano que ocupa el papel de un creador plástico conocido. Ramón en Kika realiza los collages de Dis Berlin. Ava en Julieta es una escultura y las esculturas que ejecuta son de Miquel Navarro. Incluso el estudio de esta que aparece en la película está inspirado en el de aquel. La madre de Rosa en Todo sobre mi madre pinta cuadros de Marc Chagall, aunque sea con el objetivo de la falsificación. Lo hace en su casa, la Casa Ramos de Barcelona, en la plaza de Lesseps, hito de la arquitectura modernista y donde se destaca también la réplica del sillón de madera diseñado por Gaudí.

Vera se identifica con Bourgeois y con su obra. Ambas comparten la idea del arte como medio para curar la mente ${ }^{9}$. La personalidad de una se traslada a la otra. Sabido es que la artista vivió una infancia y una adolescencia difíciles, marcadas por las infidelidades de su progenitor. Ello le hizo reflexionar sobre el papel de la mujer en la sociedad y lo plasmó en un lenguaje simbólico que remite a la represión femenina, a la sexualidad o a los problemas del patriarcado. El resultado fueron sus Femme Maison, mujeres desnudas con la cabeza atrapada en grandes casas, que son metáfora del destierro social femenino al ámbito doméstico $^{10}$. La protagonista de La piel que habito dibuja en el muro-lienzo de su aposento dos de ellas: una de las realizadas sobre lino a finales de los años cuarenta y otra en mármol blanco de 1994, insertadas entre frases de la escultora, como la ya citada: "El arte es garantía de salud", "El opio me ayuda a olvidar" o "Respiro. Sé que respiro" (Figura 4).

El conjunto no es un mero acompañamiento visual. Abajo vemos bolas gigantes de tejido similares a las de No Exit y otras veces la protagonista hace también parecidas muñecas de trapo, cosidas y remendadas, con los trozos de tela de los vestidos que le han proporcionado y ha desgarrado. Es el resultado de un nuevo punto de unión entre Vera y Louise. Las dos pueden afrontar dichas realizaciones porque tienen experiencia anterior en el manejo de telas, hilos y agujas. Esta creció en el negocio materno de la tapicería y aquella, cuando era Vicente, ayudaba en la confección de los trajes que vendía su madre en la tienda de ropa vintage de Santiago de Compostela. Lo hacía entonces cosiendo retales de diferentes colores y bajo el perfil de una mujer dibujado en el aire con alambre, a la manera de Alexander Calder. El joven queda encerrado en ese contorno, que representa la tez de una mujer y, por lo tanto, anuncia lo que le va a suceder en un futuro inmediato y que será su reclusión en otra piel, una piel femenina creada en laboratorio ${ }^{11}$ (Figura 5).

${ }^{9}$ Colomina recuerda la importancia terapéutica que le concedía Louise Bourgeois a la creación artística. Colomina, 1999: 31.

${ }^{10}$ Frémon, 2010.

11 Poyato, 2015: 287-288. 
La vinculación de La piel que habito con la obra de Louise Bourgeois va más allá. El espacio de representación que ocupa Vera remite a las Cells que dicha artista realizó en los años noventa y la postura que adopta durante sus ejercicios de yoga rememora obras de aquella, como Celda: arco de histeria y, sobre todo, Arch of Hysteria ${ }^{12}$, las cuales marcaron la aproximación de Bourgeois al surrealismo, al psicoanálisis y al interés freudiano por la "mujer histérica". Pero la figura de Arch of Hysteria, inestable y arqueada convulsivamente en el aire en expresión de la histeria, enfermedad tradicionalmente asociada a lo femenino, se convierte aquí en un hombre de genitales amputados, lo que incrementa su paralelismo conceptual con Vera ${ }^{13}$ (Figura 6).

Vera es la obra de Bourgeois hecha carne: una Femme Maison, la figura de Arch of Hysteria o una de las figurillas realizadas de telas y remiendos, cuando está en la mesa de operaciones.

Un nuevo simulacro de tableaux vivant lo tenemos en la misma película respecto a la obra de Tiziano. Dánae recibiendo la lluvia de oro de ese creador está en la casa de Elena en Carne trémula con el significado de ilustrar los hechos que relatan los personajes, delante del mismo ${ }^{14}$. Aquí, dos del citado pintor cuelgan en las paredes del pasillo del primer piso de la mansión de Ledgard, que lleva hasta el cuarto de Vera. Se trata de la Venus de Urbino y de la Venus recreándose en la música. Son, sin duda, recreaciones de la belleza femenina que tanto interesa al doctor y a cuyo interés responde también la presencia de otros cuadros en su habitación, como Memories of Olive de Alberto Vargas y Naranjas y limones de Julio Romero de Torres. Sin embargo, los lienzos de Tiziano tienen un simbolismo más contundente. Ambos aparecen justo antes de la presentación de Vera sobre su cama. A veces, Ledgard, vestido de negro, se sienta a los pies de ella y las dos figuras rememoran la misma composición de la segunda pintura del italiano. Otras veces, es observada por el doctor y se nos muestra a la manera de la Venus de Urbino, aunque en este caso, esté entretenida con la lectura de Escapada, la novela de la escritora canadiense Alice Munro, que le entregó el ama de llaves-carcelera Marilia (Marisa Paredes) y en la que se basa el guion de Julieta ${ }^{15}$.

Pero hay más representaciones pictóricas en esa casa-clínica. Unas son simples elementos de ornato, como Paisagem com ponte de Tarsila do Amaral, el cual se distingue en el flash-back en el que Marilia narra la historia de Ledgard y Gal, quedando el rostro de esta recortado en el cuadro. En la misma línea decorativa,

12 Parés Pulido, 2014: 331.

13 Cabello Ruiz, 2014: 43.

14 Poyato, 2014:105.

15 Tal entrega está llena de significado. El texto de Alice Munro habla de mujeres y de sus sentimientos. No es, por lo tanto, una lectura cualquiera que se facilita a Vera para que se entretenga. Se le da de forma intencionada y con un objetivo concreto: que vaya conociendo cuál será su carácter bajo su nueva condición femenina. 
destacan los motivos florales de Jorge Galindo ${ }^{16}$, Pigalle, Rosemary Rose y Spek's Yellow, que vemos al lado de los tizianos. En el despacho del doctor, distinguimos Perdidos en Candem de Juan Uslé y, muy especialmente, tres trabajos de Juan Gatti, titulados Ciencias Naturales, colocados de forma continua detrás del escritorio. Los pintó expresamente para la película y uno de ellos sirvió de cartel alternativo. Los tres desarrollan el mismo motivo: partes del cuerpo humano sin piel, hecho músculo-vena, puesto en relación con la naturaleza y rodeado de flores, mariposas, periquitos y flamencos. Recuerdan a las ilustraciones del siglo XIX, realizadas por médicos y científicos, que servían para estudiar la taxonomía de las plantas y animales. Por lo tanto, están ahí para referenciar la actividad profesional de Ledgard y sus reconstrucciones de piel humana. Con otros significados, destaca Dionisos encuentra a Ariadna en Naxos de Guillermo Pérez Villalta, que decora el dormitorio del protagonista masculino. Pertenece a Pedro Almodóvar, cuelga en su despacho y ha sido considerablemente ampliado para incluirse en $L a$ piel que habito. Lo protagonizan las citadas figuras sin rostro, rodeadas de motivos vegetales y marinos. Remite, así, a "la masa informe de la faz de Gal, quien no soporta verse en el espejo"17. También puede ilustrar la relación entre Vera y el doctor, ya que mientras Dionisos brinda con vino, el médico ofrece opio. Representa el momento en el que Dionisos encuentra a Ariadna en la isla de Naxos, donde ha sido abandonada por Teseo después de que, según la leyenda, fuese ella la que ideara el plan para derrotar al minotauro y poder salir del laberinto. Esos triunfos de Ariadna no son ajemos a los que consigue Vera al final del filme, lo que justifican la presencia de la pintura y su valor de significado de la acción. Navarrete-Galiano destaca una cierta similitud entre la citada obra y El nacimiento de Venus de Botticelli, básicamente por la inclusión de las figuras en la naturaleza, y ello le da pie para afirmar que el cuadro en la película es una "clara alusión alegórica al nacimiento de Vera, una mujer nueva, que también es creación de un artista" $"$.

${ }^{16}$ La presencia de Jorge Galindo ha continuado en las películas de Pedro Almodóvar. En Dolor y gloria volvemos a ver sus composiciones florales y es el autor del retrato de Salvador Mallo de niño, que pinta el albañil sobre un saco de cemento y que el retratado encuentra, ya de adulto, en una exposición en Madrid. También ha guiado la actividad pictórica del director, concretada en una serie de cuadros de gran formato, realizados por ambos a partir de las fotografías de bodegones y flores almodovarianas, y presentados en las exposiciones "Flores de la periferia" (Centro Andaluz de Fotografía, Almería, del 28 de junio al 29 de septiembre de 2019) y "Flores. Pedro Almodóvar y Jorge Galindo" (Tabacalera, Madrid, del 21 de noviembre de 2019 al 26 de enero de 2020).

17 Sánchez Noriega, 2017: 57.

18 Navarrete-Galiano, 2012: 84. 


\section{MÁS ALLÁ DE LA PINTURA Y LA ESCULTURA}

En algunos casos, el color y diseño de los decorados alcanzan un significado narrativo que complementa, incluso sustituye al de las esculturas o pinturas presentes en los mismos. Lo constata Julieta. La protagonista vive en tres apartamentos diferentes de la capital, que son expresión clara de su estado de ánimo en cada momento ${ }^{19}$. Las decoraciones cambian. El color de las paredes y los otros elementos de atrezo marcan las diferencias. El primero, en el cual se establece con su hija todavía casi niña, está empapelado con llamativos motivos en rojo, de aire setentero, que recuerda al de la casa barcelonesa de Manuela (Cecilia Roth) en Todo sobre mi madre ${ }^{20}$. Resulta un tanto agobiante, pero derrocha vida por los cuatro costados y la luz entra a raudales a través de las ventanas que dan al exterior.

Allí empieza una nueva vida para las dos. Cuando desaparece Antía, Julieta queda sumida en la más profunda tristeza. Destruye todas las pertenencias de su hija y decide enterrar su memoria. Quiere que ningún objeto ni emplazamiento le recuerden a ella. No desea saber nada del pasado. Cambia de barrio y de piso. Pasa a vivir a un nuevo apartamento, absolutamente impersonal y lejos del primero. Se trata de un amplio espacio minimalista, de paredes blancas, muebles de formas limpias y neutras, sin ayer y, sobre todo, opuesto, en decoración al anterior porque los sentimientos de la protagonista en uno y otro tiempo de su existencia son también distintos. Sus horas las marca un reloj colocado en la cocina, similar a los diseñados por George Nelson para Vitra.

La nueva casa exterioriza su interior y su blanco silencioso y austero refleja el vacío. En un momento determinado tiene noticias de que su hija está viva. Entonces vuelve al edificio del apartamento decorado con exagerados papeles pintados en rojo, que habitó con Antía cuando se trasladaron a Madrid. Alquila un piso en la misma casa, bastante parecido al primero en estructura, luminosidad y con similar arco en el pasillo. Ocupa la segunda planta y en él es la actriz Emma Suárez quien desempeña el rol de la Julieta protagonista, en tanto que el anterior

${ }^{19}$ Fueron escenarios construidos en el interior de un edificio real de Madrid, situado en el número 19 de la calle Fernando VI, en el barrio de Justicia. El hecho de que estuviese deshabitado y en rehabilitación cuando tuvo lugar el rodaje, permitió montar los decorados de las tres viviendas dentro del mismo y no en estudios cinematográficos propiamente dichos. Camarero Gómez, 2016: 31.

${ }^{20}$ López, 2017. Los enclaves en los que habita Manuela en Todo sobre mi madre revelan, igualmente, su situación personal. "Al principio de la película vive con un hijo en un piso minimalista y funcional, con muchas líneas rectas, en Madrid. Cuando se instala en Barcelona, alquila un apartamento con llamativo papel pintado de grandes lunares. El espacio doméstico se modifica no solo por su traslado de Madrid a Barcelona, sino también por la propia alteración de su estado emocional a raíz del atropello de su hijo". Sanderson, 2010: 143. 
estaba en la tercera planta y la Julieta protagonista que lo ocupaba, la interpreta Adriana Ugarte. Sin embargo, hay una diferencia fundamental entre ellos, que radica en el deterioro y en el tono de las paredes. Este, el tercer piso que habita, está pintado en verde, el color de la esperanza, y visiblemente abandonado. En dicho espacio, es donde decide esperar a su hija. El tiempo pasa y el apartamento sigue tan desnudo como cuando lo vio por primera vez. Casi el único mueble que destaca en el salón es una sencilla mesa en cristal de diseño danés, totalmente desprovista de ornamentación, donde escribe a Antía y le cuenta todo lo que no le contó cuando vivían juntas. No hay pinturas en las paredes porque la propia imagen es un cuadro en sí misma. Todo el protagonismo lo alcanza el balcón entre-abierto del fondo. Es un foco de luz procedente del exterior, que ilumina sutilmente el encuadre y que se convierte en punto de fuga ${ }^{21}$. Sobre la chimenea está la escultura de El hombre sentado que, según el guion, esculpió la amiga de la protagonista, Ava, y se la regaló tiempo atrás (Figura 7). Esta la ha tenido siempre con ella y la ha ido embalando y desembalando en cada traslado. Se trata, en realidad, de una obra de Miquel Navarro, que pertenece a Almodóvar ${ }^{22}$ y se integra en el argumento con identidad propia. Es un bronce bañado en terracota. Muestra a un hombre sentado con el pene cortado. Habla por sí sola de otra amputación: la personal que ha supuesto para Julieta la desaparición de Antía. Es una clave y una superstición. Un amuleto y un enigma.

Esta no es la única obra de arte contemporáneo propiedad del cineasta que entra en el filme. En la casa de paredes blancas, que habita Julieta cuando desaparece su hija, destaca el póster de la exposición de Lucian Freud, con su autorretrato, celebrada en la National Portrait Gallery de Londres, en 2012. Su presencia no es casual. Nadie como este conocido representante de la figuración -con permiso de Francis Bacon- ha representado mejor los sentimientos de sus retratados y está ahí para referenciar los de la protagonista, estableciéndose un diálogo simbólico-metafórico entre detrás y delante, entre la pieza expuesta en el set de rodaje y el personaje fílmico. Ahora bien, la simbología cromática realza estos trabajos y está por encima de ellos en la película.

${ }^{21}$ Camarero, 2017: 50.

${ }^{22}$ Pedro Almodóvar y Miquel Navarro se conocieron en el Madrid de los años ochenta y, con el tiempo, han consolidado su amistad. Pedro siempre había expresado su deseo de que esculturas de Miquel aparecieran en alguna de sus películas. Lo cumplió parcialmente en Carne trémula, donde vemos varias figuras de pequeño tamaño de este autor en una estantería del apartamento de Elena y David (Javier Bardem), pero pasaban casi desapercibidas y no iban más allá de formar parte del atrezo. Con un sentido igualmente decorativo, otra escultura de Miquel Navarro, de mayor tamaño, se integra en el decorado de Dolor y gloria y la vemos en el fondo del pasillo del piso de Salvador Mallo (Antonio Banderas) cuando lo recorre con su madre anciana (Julieta Serrano). En Julieta las cosas son distintas. 


\section{EL ARTE CONTEMPORÁNEO EN DOLOR Y GLORIA: NUEVOS SIMBOLISMOS Y SIGNIFICADOS}

Dolor y Gloria es el testimonio vital de Pedro Almodóvar. El protagonista, Salvador Mallo, es un director de cine ya entrado en cierta decadencia física, que podría interpretarse como el alter ego de aquel. Esa identidad entre un personaje y otro se da también en los espacios que habitan. Así, la casa del protagonista de la ficción se reconstruyó en estudio, pero muy igual a la de Pedro en la realidad y provista de casi todo lo que tiene la auténtica ${ }^{23}$. Muebles, pinturas, esculturas y otros objetos son los del director manchego, como el aparador de Fornasetti; las butacas Utrecht, diseñadas por Gerrit T. Rietveld para Cassina; la cómoda de madera reciclada de Piet Hein Eek; la tostadora Smeg en estilo vintage; la taza de Hermes; la puerta de vidrio de Patricia Urquiola en la cocina o la lámpara Eclisse de Artemide en la mesilla de noche del dormitorio de la madre ${ }^{24}$. Dan "modernidad" al espacio de representación y hablan de status, distinción y gusto estético de sus dueños.

Sin embargo, lo que más llama la atención es la presencia de bastantes esculturas y pinturas que son del cineasta y algunas de las cuales ya aparecían en otras de sus películas. “Parece un museo!”, dice Federico (Leonardo Sbaraglia) cuando llega al piso, a lo que Salvador responde: "Lo que he ganado, lo he invertido en esta casa y en estos cuadros" ${ }^{25}$. Podría ser, perfectamente, lo que hubiese respondido Pedro y sería verdad.

Todas ellas entran constantemente entre los planos. La mayoría son realizaciones de los creadores que han tenido presencia en otros filmes y que forman parte de los recuerdos personales de Almodóvar, que rememora en la película. Es lógico que, si esta es, argumentalmente, una aproximación a una biografía, tengan lugar en la misma, las obras que han acompañado al "biografiado" o que hubiese deseado que le acompañasen en su recorrido vital. Por lo tanto, la selección no pudo ser más personal y significativa de sus gustos y sentimientos. Así, no faltan composiciones de Pérez Villalta, integrante de la Nueva Figuración madrileña y que ya realizó un mural inspirado en la capilla Sixtina para la habitación de Sexilia (Cecilia Roth) en Laberinto de pasiones. Era, en realidad, la casa de

${ }^{23}$ No es la primera vez que la casa de Almodóvar se traslada a sus filmes, aunque sea de manera menos explícita, y así lo ha reconocido él mismo: "Para mí, una cosa muy importante en una película es el atrezo, los decorados. Si tú pides una mesa y una máquina de escribir, no vale cualquier mesa ni cualquier máquina de escribir. Los objetos tienen que estar vividos en alguna medida. Cuando pensamos en el piso de Pablo Quintero (Eusebio Poncela) en La ley del deseo, a los decoradores les puse como referencia mi propia casa, no para que la copiaran, pero sí para que captaran el aire", y la vivienda de ese otro director de cine en la ficción respira igual atmósfera que la de Pedro. Vidal, 1989: 243.

24 Vázquez, 2019.

25 Almodóvar, 2019: 127. 
Pablo Pérez Mínguez, autor de las mejores imágenes fotográficas de la Movida. Aquí distinguimos dos de sus cuadros y el guion da fe que existen en ese espacio doméstico porque los piden para una ficticia exposición en el Guggenheim de Bilbao. Mallo se niega a prestarlos. Son Artista viendo un libro de arte, muy característico del estilo de su autor con la repetida figura del "artista" sin rostro, vivo colorido y recargamiento ornamental de raíz oriental, que se encuentra en el Centro Andaluz de Arte Contemporáneo de Sevilla; y el repetido Dionisos encuentra a Ariadna en Naxos (Figura 8).

Volvemos a ver obras de Dis Berlin en la casa de Mallo. En La ley del deseo, ¡Átame!, Tacones lejanos, Kika, La mala educación o Julieta ${ }^{26}$ estaban, mayoritariamente, sus famosos collages y fotomontajes de raíz figurativa, dotados de gran fuerza narrativa e iconográfica. Muchos constituyen claros ejemplos kitsch de reutilización de la iconografía religiosa. Baste recordar el dispuesto encima del lecho de Ramón Vargas (Álex Casanovas) en Kika, con esa mezcla tan característica de los atrezos almodovarianos entre estampas religiosas y fotos de las stars cinematográficas. Igualmente, el que adorna el frente, sobre la cama, del dormitorio donde conviven Marina (Victoria Abril) y Ricki (Antonio Banderas) en ¡Átame! con seis imágenes de Sagrados Corazones, tres de la Virgen arriba y tres de Jesucristo abajo ${ }^{27}$. Otros optan por la exuberancia más radical de motivos y personas. Lo demuestra su famoso Mujer frutero, que forma parte de la colección particular de Pedro y aparece sobre el cabecero de la alcoba de Kika en la película del mismo nombre. Más recientemente, Dis Berlin ha tendido a priorizar las realizaciones escultóricas y en Dolor y gloria se presenta esta actividad. Así hay varias esculturas suyas más recientes, pero no han sido creadas especialmente para la película. Pertenecen al director. Se trata de una de sus estilizadas y habituales Columnas Cósmicas, colocada debajo del cuadro Máscaras de Maruja Mallo, Castillo en el aire y Llama de la concentración, en vivos colores y que integra las Esculturas del paraíso.

Tampoco faltan trabajos de Sigfrido Martín Begué, que fue otro de los iconos de la Movida madrileña. En el despacho de Almodóvar está su famosa Máquina de hacer cine, que también decora el de otro director de la ficción: el de Enrique Goded en La mala educación. Algunos de los motivos incluidos en esta obra formarían parte de la particular interpretación del futurismo que llevó a cabo, algo después, en su Autómata Anticlaro de Luna. Le ha caracterizado la revisión de obras conocidas de nuestro patrimonio artístico, similar a la practicada por el Equipo Crónica y hecha siempre con tono realista y cierto sarcasmo. En esa línea

${ }^{26}$ En este caso, suyo es el corazón del tatuaje con la "A" de Antía y la "J" de Julieta que lleva el personaje de Xoan (Daniel Grao) y uno de los cuadros marinos, En mares lejanos, recuperado por la joven para su habitación, cuando viene a vivir a Madrid con su madre.

27 Yarza, 2007: 109-124. 
se incluyen las obras que vemos en Dolor y gloria. Son también de Almodóvar. Una es Las costureras, peculiar y personal homenaje a las Hilanderas de Velázquez, que ya aparecía en la consulta del psiquiatra a la que acude Benigno (Javier Cámara) en Hable con ella, y El olfato-Santa Casilda, actualización de la Santa del mismo nombre de Zurbarán. Ambos cuadros destacan en el salón de Salvador Mallo, junto con los tótems de Ettore Sottsas. Es el fondo ante el que se mueve el personaje central.

La obra de Juan Gatti, otro clásico en el cine almodovariano, también está presente en Dolor y gloria. Son suyas las infografías que ilustran la enumeración, en voz en off y al principio de la película, de las numerosas dolencias que sufre el protagonista; y las animaciones sobre las que se disponen los títulos de crédito iniciales, que traen a la memoria la portada del álbum Elysium del dúo Pet Shop Boys; pero, sobre todo, las formas y el colorido del papel mármol típico de las ediciones antiguas de los libros, lo que implica un homenaje al carácter literario de la narración, que vertebra todo el filme. Igualmente, ha realizado los carteles que cuelgan en las paredes del chalecito de Alberto Crespo (Asier Etxeandia) y que comparten espacio con una reproducción de la Pera de Enzo Mari, de 1963, y perteneciente a la serie Della Natura, igual que la Mela, ya comentada, que decoraba el hogar de Chicas y Maletas, dentro de Los abrazos rotos. Son los de la película ficticia Sabor, La gata sobre el tejado de zinc y Hamlet, que aparecen, además, en otros momentos. La presencia de estas obras no es baladí. Están ahí porque identifican la actividad profesional de quien habita la vivienda. Definen el espacio del actor.

Completan el elenco de los habituales: Flores de Jorge Galindo, abstracciones de Miguel Ángel Campano y figuraciones de Manolo Quejido, presentes en La piel que habito y La ley del deseo, respectivamente. Se incorporan, incluso, algunos de los coloristas bodegones fotográficos realizados por Pedro Almodóvar en la estética de Giorgio Morandi, protagonizados por objetos de su vida cotidiana y su propio gato, que expuso en, 2017 y 2018, en las Fresh Gallery y Marlborough de Madrid.

Todo ello demuestra el carácter biográfico de las obras de arte incluidas, acorde con la narración. La mayoría, las hicieron artistas destacados de la escena madrileña cercanos a la Movida. Algunos, vinculados al grupo Los Esquizos de Madrid, creadores de la denominada Nueva Figuración madrileña. Informan de la personalidad y gusto del cineasta. Hablan de él. Pero tienen además un significado nuevo y distinto: son referentes espaciales y temporales. Nos sitúan en el Madrid de los ochenta, que rememora la película desde el presente.

La cámara no enfoca ni se detiene en ninguna de las citadas piezas. Solo lo hace con Racimo de uvas de Maruja Mallo, que destaca en la cocina recreada junto a recortes de fotografías de El Guernica de Picasso y El gran masturbador de Dalí. Almodóvar admira a esta artista y le rinde homenaje poniendo su apellido a su protagonista: Salvador Mallo. Le llamó la atención en la exposición Maruja 
Mallo: Creación y Orden, celebrada en la madrileña galería Guillermo de Osma, en 2017. Pero no llegó a comprarla. Se la quedó el galerista y la dejó para lucir en el decorado de Dolor y gloria, "con lo que fue un modo de tenerla" 28 . Por ello, seguramente, la destaca, más que otra de la misma creadora, como Máscaras, que si forma parte de su colección particular y distinguimos en la entrada de la vivienda.

En definitiva, las obras de arte integradas en los decorados de las películas del director manchego tienen valor de significado. Definen los espacios de representación, caracterizan las actitudes de los protagonistas, aportan las claves temáticas, ilustran la acción, diferencian las clases sociales y referencian tiempos y lugares. Son "claves para descifrar".

Fecha de recepción: 29 de octubre de 2019

Fecha de aceptación: 13 de abril de 2020

\section{BIBLIOGRAFÍA}

Almodóvar, Pedro (1993): "Los decorados de Kika". En: Elle decoration, 24, p. 66. (2019): Dolor y gloria. Barcelona: Reservoir Books.

Arroyo Fernández, María Dolores (2011): "Pepi, Luci, Bom... Transgresión sexual y cultura popular". En: Icono14, A9/ESP, pp. 256-274.

Cabello Ruiz, María Teresa (2014): "Intertextualidad en La piel que habito: Louise Bourgeois según Pedro Almodóvar”. En: Sesión no numerada: Revista de letras y ficción audiovisual, 4, pp. 34-46.

Camarero Gómez, Gloria (2017): "Literatura y arte en Julieta de Pedro Almodóvar". En: DeSignis, 27, pp. 45-52.

(2020): Madrid en el cine de Pedro Almodóvar. Madrid: Akal, [4 edición. ${ }^{\text {a }}$ edición 2016].

Colomina, Beatriz (1999): "La arquitectura del trauma". En AA.VV.: Louise Bourgeois. Memoria y Arquitectura. Madrid: Museo Nacional Centro de Arte Reina Sofía, pp. 29-52.

Frémon, Jean (2010): Louise Bourgeois. Mujer Casa. Barcelona: Elba.

Huguet, Montserrat/Camarero, Gloria (2000): "Reconstrucción histórica de una sociedad perdida: La edad de la inocencia". En: Film \& Historia, 10/3, pp. 139-158.

López, Ianko (2017): “Almodóvar: obsesión decorativa en 10 puntos". En: AD. Architectural Digest, 31-8-2017. https://www.revistaad.es/arte/articulos/almodovar-obsesion-decorativa-en-10-puntos/19257 (9-9-2019).

\footnotetext{
${ }^{28}$ López, 2019.
} 
López, Ianko (2019): “Dolor y gloria permite a Almodóvar tener por fin el cuadro que nunca pudo comprar". En: El País, 14-3-2019.

Navarrete-Galiano, Ramón (2012): “La piel que habito: nueva creación literaria, pictórica y escultórica de Almodóvar”. En: Crespo Fajardo, José Luis (coord.): Arte y cultura digital. Planteamientos para una nueva era. Málaga: Universidad de Málaga, pp. 74-86.

Ortiz, Áurea/Piqueras, María Jesús (1995): La pintura en el cine. Cuestiones de representación visual. Barcelona: Paidós.

Parés Pulido, Marina (2014): "Intertextualidad en La piel que habito: pintura, escultura y dibujo". En: Fotocinema, 9, pp. 325-360.

Poyato, Pedro (2012): "El cine en el cine: Los abrazos rotos (Pedro Almodóvar, 2009)". En: Fotocinema, 5, pp. 7-23.

- (2014): "La escritura del «Almodrama»". En: Poyato, Pedro (ed.): El cine de Almodóvar. Una poética de lo trans. Sevilla: Universidad Internacional de Andalucía, pp. 99-124.

(2015): "Programas iconográficos en La piel que habito (Almodóvar, 2011)". En: Anales de Historia del Arte, 25, pp. 283-302.

Sanderson, John D. (2010): "Sirk en Almodóvar: claves de una dirección artística”. En: Sanderson, John D./Gorostiza, Jorge (coords.): Constructores de ilusiones. La dirección artística cinematográfica en España. Valencia: Ediciones de la Filmoteca, pp. 133-159.

Sánchez Noriega, José Luis (2017): Universo Almodóvar. Madrid: Alianza.

Thibaudeau, Pascale (2013): "El cuerpo, la piel y la pantalla: los territorios habitados por Pedro Almodóvar". En: Fotocinema, 7, pp. 192-208.

Umbral, Francisco (1981): “Costus". En: El País, 6-11-1981.

Vázquez, Anabel (2019): "Así son los interiores de Dolor y gloria, de Almodóvar". En: AD. Architectural Digest, 5-9-2019. https://www.revistaad.es/decoracion/ articulos/interiores-dolor-y-gloria-ultimo-almodovar/22449 (18-10-2019).

Vidal, Nuria (1989): El cine de Pedro Almodóvar. Barcelona: Destino [2a edición. $1^{\mathrm{a}}$ edición 1988].

Yarza, Alejandro (1997): "Iconografía religiosa y estética camp en ;Átame! de Pedro Almodóvar”. En: Revista canadiense de estudios hispánicos, 1, pp. 109124. 


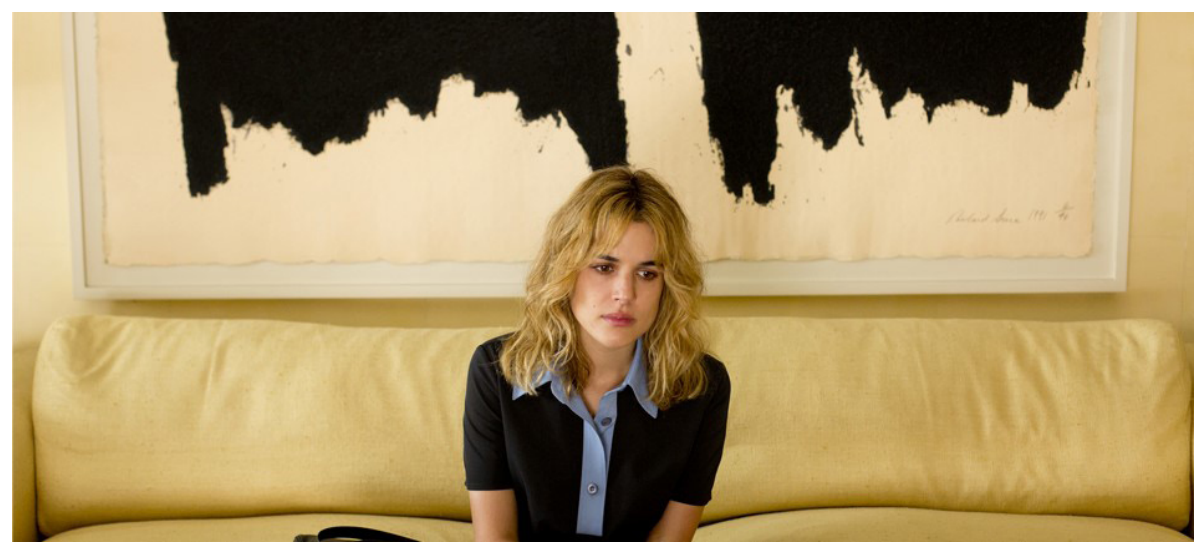

Figura 1. Reykjavík de Richard Serra en Julieta. C EL DESEO DA SLU. Foto: Manolo Pavón.

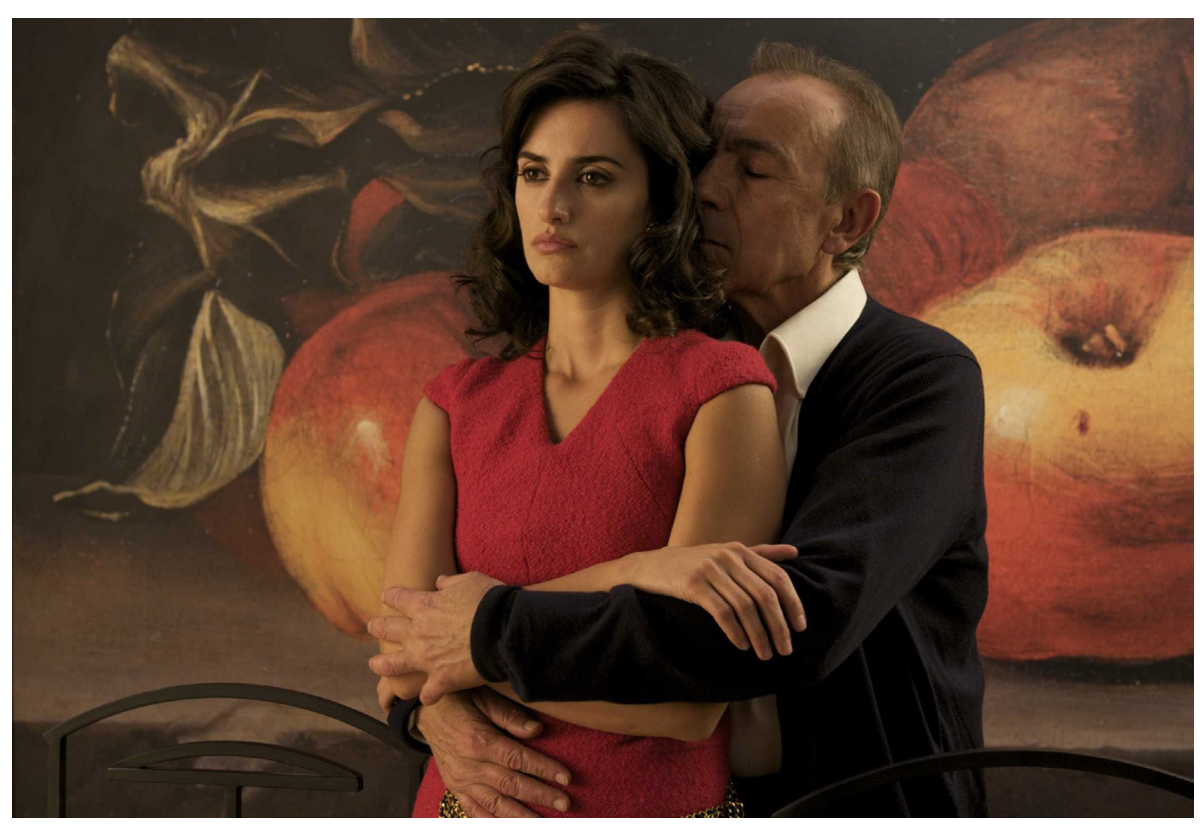

Figura 2. Manzanas de Juan Bautista de Espinosa en Los abrazos rotos.

(c) EL DESEO DA SLU. Foto: Manolo Pavón. 


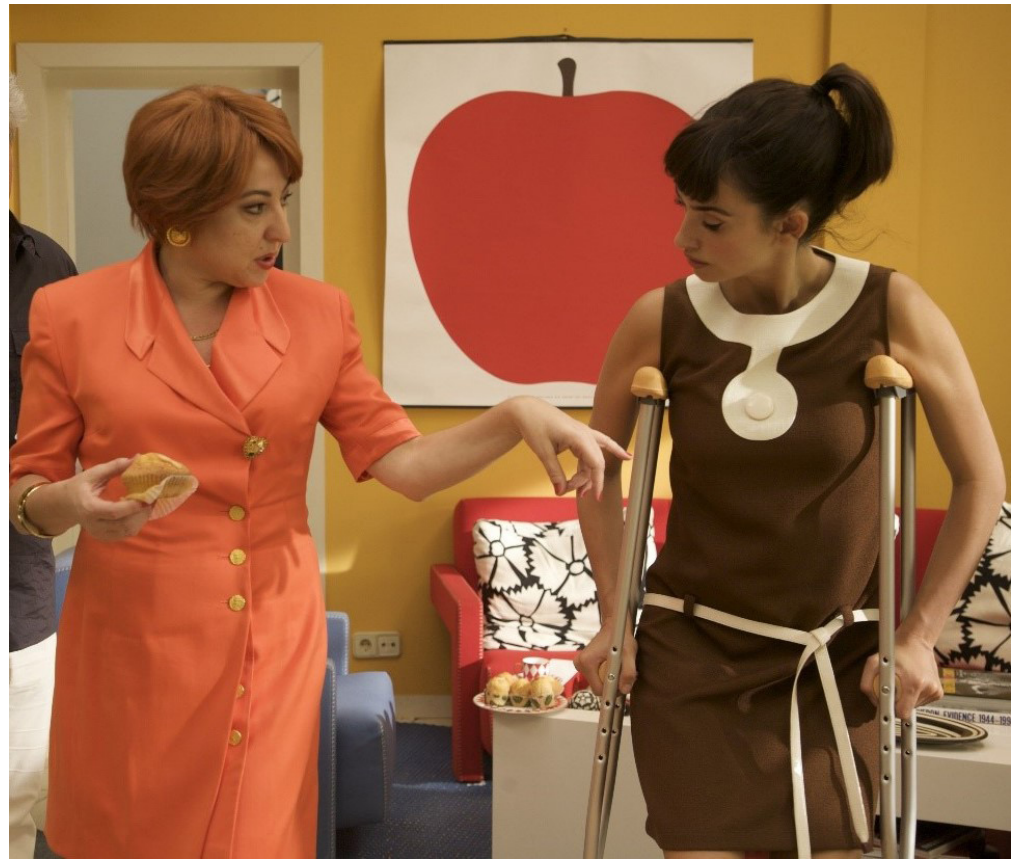

Figura 3. Mela de Enzo Mari en el filme Chicas y maletas, integrado en Los abrazos rotos. (C) EL DESEO DA SLU. Foto: Paola Ardizzoni y Emilio Pereda.

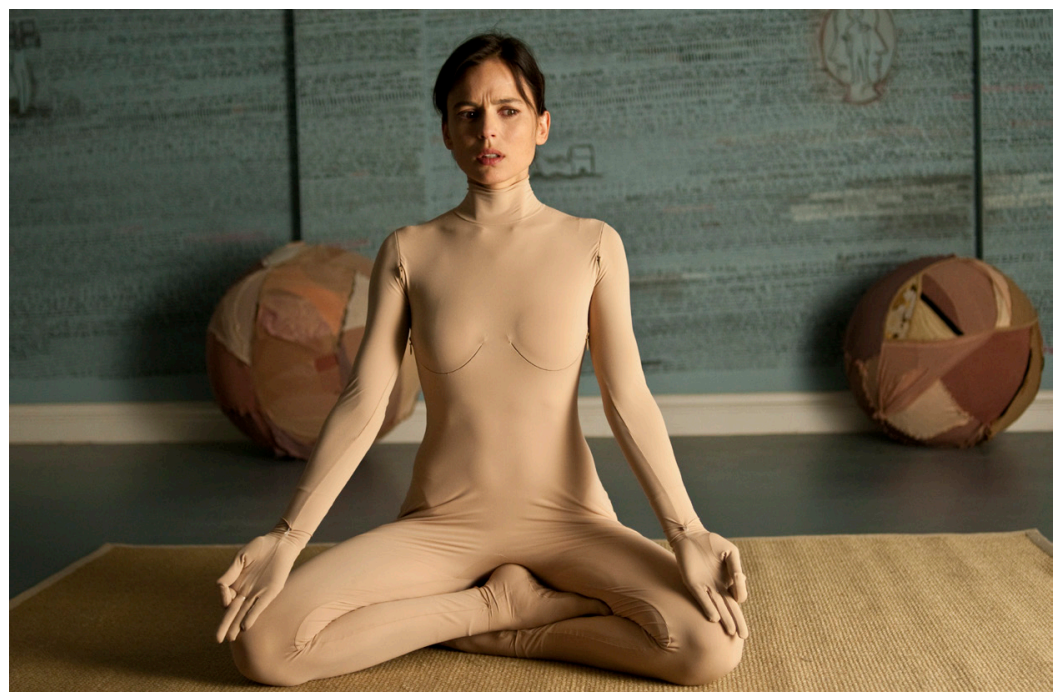

Figura 4. La piel que habito. (C) EL DESEO DA SLU. Foto: José Haro. 


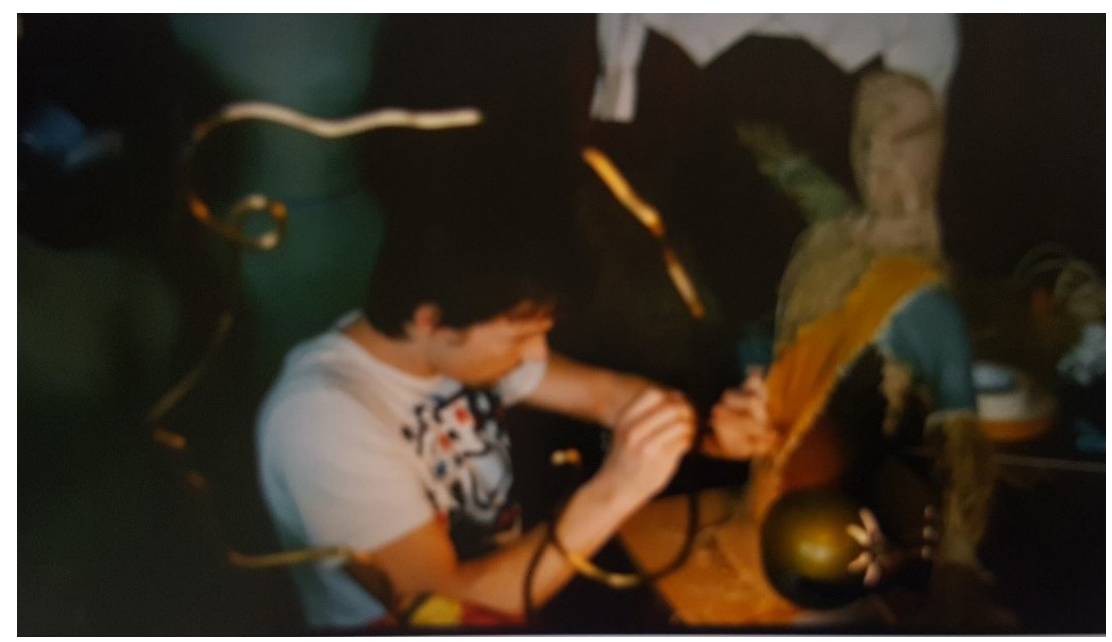

Figura 5. La piel que habito. (C) EL DESEO DA SLU.

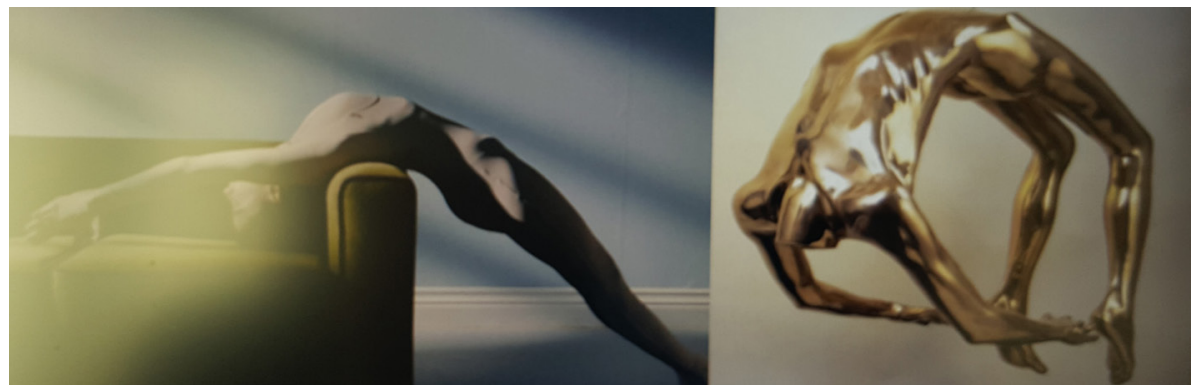

Figura 6. Vera practicando yoga en La piel que habito (@) EL DESEO DA SLU. Foto: Lucía Faraig) y Arch of Hysteria de Louise Bourgeois. 


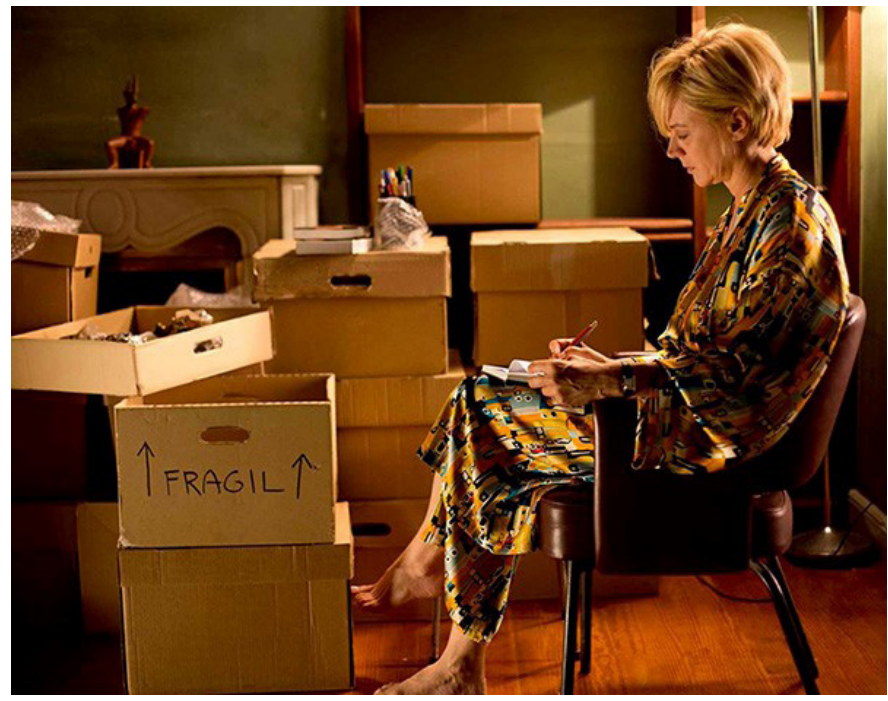

Figura 7. El hombre sentado de Miguel Navarro en Julieta. (c) EL DESEO DA SLU. Foto: Manolo Pavón.
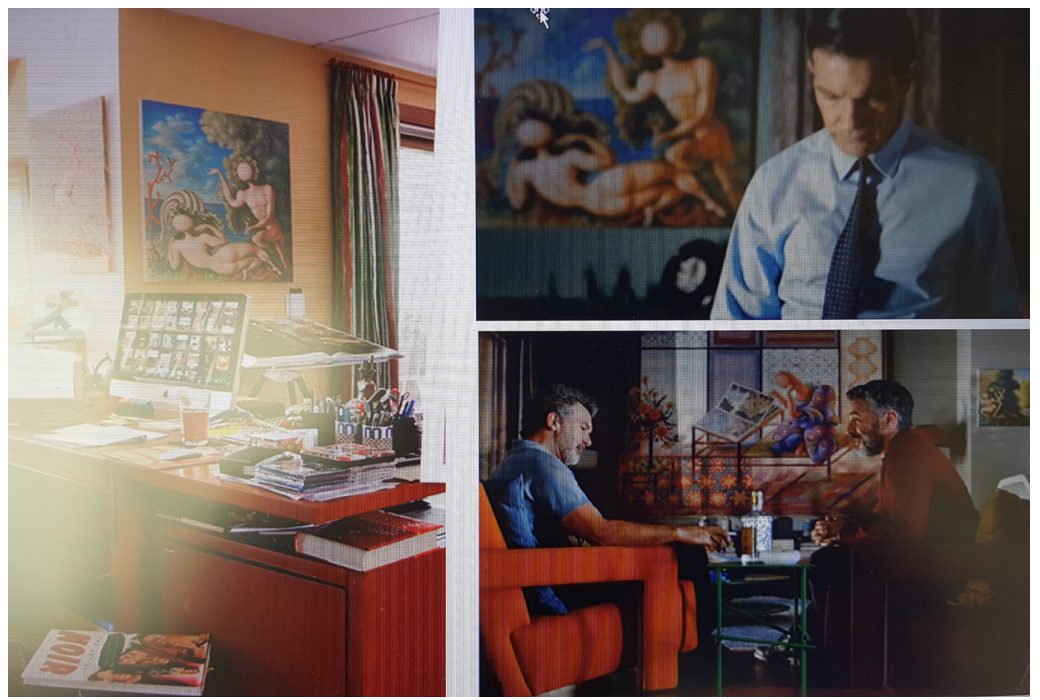

Figura 8. Dionisos encuentra a Ariadna en Naxos de Guillermo Pérez Villalta en su ubicación real en el despacho de Pedro Almodóvar (Vanity Fair USA. Giacomo Bretzel) y copias en sus ubicaciones ficticias: dormitorio de Robert Ledgard en La piel que habito

(C) EL DESEO DA SLU) y salón de Salvador Mallo en Dolor y gloria (C) EL DESEO

DA SLU. Foto: Manolo Pavón), junto con Artista viendo un libro de arte, también de Pérez Villalta. 